\title{
SABER DEL OTRO: ESCRITURA Y ORALIDAD EN EL FACUNDO DE D. F. SARMIENTO
}

\author{
POR \\ JULIO RAMOS \\ Emory University
}

Si bien durante las guerras de independencia las virtuales clases dirigentes latinoamericanas habían logrado articular un consenso - «nosotros», que adquiere espesor en oposición al enemigo común: España-, tras la instalación de los nuevos gobiernos, las contradicciones fundamentales reemergen a la superficie de la vida social. Los Estados debían consolidarse, delimitar los territorios y generalizar la autoridad de una ley central, capaz de someter las particularidades en pugna bajo el proyecto de una nueva homogeneidad, incluso linguística, nacional. «La República Argentina es una e indivisible» ${ }^{1}$, señala Sarmiento. Sin embargo, la realidad era otra: la fragmentación interna deshacía el proyecto de consolidación del sujeto nacional, casi siempre imaginado sobre el calco de modelos extranjeros.

Tras la victoria sobre el antiguo régimen se intensificaba el caos, en la medida en que las rígidas instituciones coloniales $-\mathrm{y}$ el consenso antiespañol-- perdían vigencia. Escribir, a partir de 1820 , respondía a la necesidad de superar la catástrofe, el vacío de discurso, la anulación de estructuras, que las guerras habían causado. Escribir, en ese mundo, era dar forma al sueño modernizador; era «civilizar»: ordenar el sinsentido de la «barbarie» americana ${ }^{2}$.

${ }^{1}$ D. F. Sarmiento, Civilización y barbarie. Vida de Facundo Quiroga (1845). Manejamos la edición de la Editora Nacional (Madrid, 1975). Entre paréntesis señalaremos las páginas de las citas.

${ }^{2}$ Una lectura general de las funciones de la escritura en el siglo xIx se encuentra en Angel Rama, La ciudad letrada (Hanover: Ediciones del Norte, 1984). Véase también Jean Franco, «La heterogeneidad peligrosa: escritura y control social en vísperas. de la independencia mexicana», en Hispamérica, $34-35$ (1983), pp. 3-34. 
En un texto fundamental, Recuerdos de provincia, recuerda Sarmiento:

Nosotros, al día siguiente de la revolución, debíamos volver los ojos a todas partes buscando con qué llenar el vacío que debían dejar la inquisición destruida, el poder absoluto vencido, la exclusión religiosa ensanchada ${ }^{3}$.

Ante la carencia de modelos, el discurso se desliza, casi automáticamente, hacia su norte: «Norte América se separaba de Inglaterra sin repudiar la historia de sus libertades» (Recuerdos, p. 92). El intelectual, en Sarmiento, se legitima volviendo «los ojos a todas partes, buscando con qué llenar el vacío». Llenar vacios: poblar desiertos, construir ciudades, navegar los ríos. La imagen del transporte, a lo largo del Facundo, es privilegiada: condensa el proyecto de someter la heterogeneidad americana al orden del discurso, a la racionalidad (no sólo verbal) del mercado, del trabajo, del sentido ${ }^{4}$.

No obstante, el discurso estaba en otra parte: también había que transportarlo. En Sarmiento, el intelectual opera en función del viaje importador del discurso. Viaje a Europa o Norte América, «buscando con qué llenar el vacío».

Sarmiento: «Hay regiones demasiado altas, cuya atmósfera no pueden respirar los que han nacido en las tierras bajas» ${ }^{5}$. El viajero va de 10 bajo a lo alto, mediando entre la desigualdad. Va con

1a idea de que vamos en América en mal camino, y de que hay causas profundas, tradicionales, que es preciso romper, si no queremos dejarnos arrastrar a la descomposición, a la nada, y me atrevo decir a la barbarie, fango inevitable en que se sumen los restos de pueblos y razas que no pueden vivir, como aquellas primitivas cuanto informes creaciones que se han sucedido sobre la tierra, cuando la atmósfera se ha cambiado (Viajes, p. 49).

${ }^{3}$ Recuerdos de provincia (1850) (Buenos Aires: Editorial Sopena, 1966), p. 92.

${ }^{4}$ Por supuesto, el transporte y la red de la comunicación constituye una condición material de posibilidad del desarrollo capitalista: de ahí el énfasis no sólo en Sarmiento, sino en todos los patricios modernizadores. Pero a la vez constituye un icono, una representación de la coherencia, de la estructura que proyectaba el discurso racionalizador. Para una «semiótica» del transporte, cfr. Michel de Certeau, «Railway Navigation and Incarceration", en The Practice of Everyday Life, trad. de S. F. Randall (Berkeley: University of California Press, 1984), pp. 111-114.

${ }^{5}$ Viajes por Europa, Africa y América (1849), en Alberto Palcos (ed.), Viajes (Buenos Aires: Hachette, s. f.), p. 51. 
Significativamente, la «bajeza» ahí ya no es sólo efecto del «vacío»: es el «fango» de las «causas tradicionales», «primitivas», «informes», incapaces de ajustarse a las exigencias del progreso. Para sacar a los suyos de la «barbarie», el intelectual viaja a las «tierras altas». El sí podía respirar en aquellas regiones altas: llevaba lecturas. Luego regresaria con la palabra traducida, llena de valor, del modelo. Si la condición del viaje en Sarmiento es el desnivel, la distancia entre lo alto y lo bajo, el proyecto de su escritura es la disolución del desajuste: cubrir el vacío. Nivelación que presuponía, a su vez, la necesidad de poblar el desierto americano con las estructuras de la modernidad: "¿No queréis, en fin, que vayamos a invocar la ciencia y la industria en nuestro auxilio, a llamarlas con todas nuestras fuerzas, para que vengan a sentarse en medio de nosotros?» (Facundo, p. 53).

Ahora bien: el transporte del sentido implica nuevos desajustes y desplazamientos. En unas lúcidas «Notas sobre Facundo», sobre el trabajo de la cita en Sarmiento, R. Piglia señala cómo la frase en francés ( On ne tue point les idées»), que, según Sarmiento, había desencadenado la escritura del Facundo ( «fundador» de una literatura nacional), es prácticamente apócrifa: «La cita más famosa del libro, que Sarmiento atribuye a Fortoul, es, según Groussac, de Volney. Pero otro francés, Paul Verdevoye, ha venido a decir que tampoco Groussac tiene razón: después de señalar que la cita no aparece en la obra de Fortoul, pero tampoco en Volney, la encuentra en Diderot ${ }^{5}$. La derivación en esa cadena borgeana de atribuciones falsas tal vez podría ir más allá de Verdevoye o de Piglia. En todo caso, Piglia demuestra cómo el mecanismo de la cita, con sus permanentes desplazamientos, es un núcleo productor del Facundo, cuya propuesta -cifrada en sus sistemáticas analogías- es, precisamente, sujetar la particularidad americana referida bajo la autoridad del modelo citado. El siguiente es un buen ejemplo:

En la Historia de Paris, escrita por G. Fouchard La Fosse, encuentro estos singulares detalles [...] Poned en lugar de la cruz de San Andrés la cinta colorada; en lugar de las rosas coloradas, el chaleco colorado; en lugar de cabochiens, mazorqueros; en lugar de 1418, fecha de aquella sociedad, 1835, fecha de esta otra; en lugar de París, Buenos Aires; en lugar del duque de Borgoña, Rosas, y tendréis el plagio hecho en nuestros días (pp. 308-309). p. 17.

' Ricardo Piglia, «Notas sobre Facundo», en Punto de Vista, año 3, núm. 8 (1980), 
La vida plagiando a la literatura. Piglia comenta:

Si Sarmiento se excede en su pasión, un poco salvaje, por la cultura es porque para él conocer es comparar. Todo adquiere sentido si es posible reconstruir las analogías entre lo que se quiere explicar y otra cosa que ya está juzgada y escrita. Para Sarmiento saber es descifrar el secreto de las analogías: la semejanza es la forma misteriosa, invisible que hace visible el sentido. La cultura funciona sobre todo como un repertorio de ejemplos que pueden ser usados como términos de la comparación («Notas sobre Facundo», p. 17).

En un primer análisis, la autoridad en Sarmiento parecería radicar afuera, en el allá europeo o norteamericano, adonde se dirige el intelectual viajero. De ahí que, por momentos, Sarmiento hable sobre la «barbarie» como si la observase a la distancia, desde un lugar de enunciación centrado en Europa ${ }^{7}$. Ese distanciamiento del mundo sobre el que se escribe es notable, sobre todo, en el manejo sistemático de retóricas y discursos etropeos en la representación del «bárbaro» americano en el Facundo:

Y la vida pastoril nos vuelve impensadamente a traer a la imaginación el recuerdo del Asia, cuyas llanuras nos imaginamos siempre cubiertas aquí y allá de las tiendas del camuco, del cosaco o del árabe (p. 81).

Sobre la particularidad americana se impone la figura (europea) del «oriental». Obsérvese, sin embargo, que el «conocimiento» que busca producir la analogía es imaginado. El discurso se desliza del mundo referido al archivo orientalista, que, como señala E. W. Said, más que una red de conocimientos de la realidad «oriental», comprueba ser un discurso históricamente ligado al expansionismo decimonónico y a la propia constitución de un territorio de identidad europeo, mediante la exclusión de los «otros» y la consecuente delimitación del campo «civilizado». Según Said, podemos leer el discurso sobre el «otro» no tanto en función de su referencialidad, sino como dispositivo de la constitución «propia» del sujeto (europeo) que produce el discurso. E1 «otro», en ese sentido, es un aspecto definitorio del imaginario europeo ${ }^{8}$.

${ }^{7}$ En cuanto a las representaciones occidentales de lo «salvaje» y lo «bárbaro», resulta valioso el trabajo de Hayden White «The Forms of Wildness: Archaeology of an Idea», en Tropics of Discourse: Essays in Cultural Criticism (Baltimore: The John Hopkins University Press, 1978), pp. 150-182, y M. de Certeau, «Montaigne's 'Of Cannibals': The Savage 'T'», en Heterologies: Discourse on the other (Minneapolis: University of Minnesota Press, 1986), pp. 67-69.

${ }^{8}$ Edward W. Said, Orientalism (New York: Vintage Books, 1978). 
La cita del orientalismo en Sarmiento es así un gesto muy significativo: proyecta, por parte de quien no es europeo, un deseo de inscribirse en el interior de la cultura occidental. Implica un lugar de enunciación -ficticio- fuera de la «barbarie» (lo no europeo), enfáticamente «civilizado». La cita de ese discurso identificador de lo europeo, de lo occidental, tiende así a obliterar el lugar de la escritura, en América, al otro lado de lo occidental, donde se produce el Facundo.

Pero el trabajo de la cita, según señala Piglia, comprueba cómo, a pesar de sí, Sarmiento desplaza y hasta cierto punto corroe la autoridad de los modelos citados. El proceso mimético —estimulado por el deseo de ser otro, el otro de tierras altas- nunca conlleva la repetición de la attoridad imitada; somete la palabra del otro europeo a una descontextualización inevitable, que a veces resulta en parodias involuntarias. Piglia:

En el momento en que la cultura sostiene los emblemas de la civilización frente a la ignorancia, la barbarie corroe el gesto erudito. Marcas de un uso que habría que llamar salvaje de la cultura, en Sarmiento, de hecho, estos barbarismos proliferan. Atribuciones erróneas, citas falsas $[\ldots]$ (p. 17).

De ahí que, para Piglia, la distancia entre Sarmiento y el saber europeo no radique tanto en su afirmación de una diferencia, sino en la corrosión de esos discursos altos en boca, digamos, de un «mal» letrado. Sarmiento escribe mal ese saber que a la vez exalta.

Si bien es cierto que una zona de ese conjunto de autoridades que llamamos Sarmiento se legitima en función del viaje importador, cuya unidad mínima de sentido sería la cita del modelo extranjero, la lectura de Piglia corre el riesgo de representar la relación entre Sarmiento y Europa, entre la escritura americana y el «capital simbólico» extranjero, en términos estrictamente negativos. Es decir, la distancia entre Sarmiento y la biblioteca europea, sugiere Piglia, es sólo un producto de la «mala cita», de un uso "salvaje» de los modelos, cuya autoridad permanecería incuestionada. La lectura de Piglia opera en función de lo que podríamos llamar la lógica - binaria- de la parodia. Lo americano (o lo argentino, en Sarmiento) vendría a registrar un punto ciego en el campo occidental: se presupone cierta noción de la diferencia como carencia o deformación de la plenitud del modelo extranjero. La lógica de la parodia tiende así a representar y clasificar cualquier productividad distinta del modelo europeo en términos de la falta o incluso de la inversión de la estructura imitada (o «mal» imitada). Y tiende así a restablecer el mimetismo que inicialmente buscaba desarmarse. Porque la inversión de una estructura 
naturaliza su campo de operaciones, presuponiendo las jerarquías de la estructura como el horizonte y límite de la crítica (del mismo modo en que la parodia configura un mimetismo a la inversa).

Sarmiento no sólo ocupa, sino que maneja, un lugar subalterno respecto a la biblioteca europea. Sobre todo después de la lectura crítica que Valentín Alsina hizo del Facundo, en que lamentaba la falta de rigurosidad historiográfica de Sarmiento, éste insistió en el carácter espontáneo de su trabajo. Continuamente, Sarmiento se refiere al libro (que se publicó, inicialmente, por entregas a un periódico, según la norma de la época) como «material de vida», como un conjunto de notas o apuntes que había, en el futuro, que reorganizar. Así explica la «informalidad» del Facundo:

Algunas inexactitudes han debido necesariamente escaparse en un trabajo hecho de prisa, lejos del teatro de los acontecimientos, y sobre un asunto del que no se había escrito nada hasta el presente [...] Quizá haya un momento en que, desembarazado de las preocupaciones que han precipitado la redacción de esta obrita, vuelva a refundirla en un plan nuevo, desnudándola de toda digresión accidental y apoyándola en numerosos documentos oficiales, a que sólo hago ahora una ligera referencia (p. 42).

También en la respuesta a Alsina («Prólogo» a la edición de 1851) reaparece esa autorreflexión, ahora apelando a la flexibilidad del ensayo:

Ensayo y revelación para mí mismo de mis ideas, el Facundo adoleció de los defectos de todo fruto de la inspiración del momento, sin el auxilio de documentos a la mano, y ejecutada no bien era concebida, lejos del teatro de los sucesos, y con el propósito de acción inmediata y militante (p. 61).

Pero aunque acepta las críticas de Alsina a la «indisciplina» del $F a$ cundo, le responde que no retocaría la «obrita», que no quería eliminar los defectos de su «civilización», «temeroso de que por retocar obra tan informe desapareciese su fisonomía primitiva y la lozana y voluntariosa audacia de la mal disciplinada concepción» (p. 62). No sería difícil encontrar estos calificativos de la «obrita» describiendo a la barbarie a lo largo del Facundo. En efecto, la barbarie es primitiva, voluntariosa, informe y mal disciplinada. Lo significativo es que los términos aquí describen la propia «obrita» de Sarmiento.

Así configura Sarmiento un lugar de enunciación subalterno, «marginal» con respecto a la biblioteca europea: 
Este estudio, que nosotros no estamos aún en estado de hacer, por nuestra falta de instrucción filosófica e histórica, hecho por observadores competentes habría revelado a los ojos atónitos de la Europa un mundo nuevo en política (p. 48).

Sin embargo, ese lugar subalterno, marginal, que asume Sarmiento, se convierte en el mecanismo de autorización de un trabajo intelectual alternativo, que enfatiza su diferencia del saber europeo:

¡Oh! La Francia, tan justamente erguida por su suficiencia en las ciencias históricas, políticas y sociales; la Inglaterra, tan contemplativa de sus intereses comerciales; aquellos políticos de todos los países, aquellos escritores que se precian entendidos, si un pobre narrador americano se presentase ante ellos con un libro, para mostrarles como Dios muestra las cosas que llamamos evidentes [...] (p. 63).

Su humildad, por supuesto, no debe engañarnos. La ironía es sutil, pero evidente. Desde el margen, el «pobre narrador» reclama un saber distinto y a veces opuesto a la «disciplina» europea. Por el reverso de los sabios europeos, Sarmiento propone la tarea del escritor americano:

Hay una justicia ejemplar que hacer y una gloria que adquirir como escritor argentino: fustigar al mundo y humillar la soberbia de los grandes de la tierra, llámense sabios o gobiernos (p. 64).

La labor del «pobre narrador americano» acaso resultara «indisciplinada» o «informe» (atributos de la barbarie). Pero esa «espontaneidad», esa cercanía a la vida, ese discurso «inmediato» era necesario para representar el «mundo nuevo» que el saber europeo, a pesar de sus propios intereses, desconocía. Según veremos luego, para Sarmiento había que conocer toda esa zona de la vida americana - la barbarie- que resultaba irrepresentable para la «ciencia» y los «documentos oficiales». Había que oír al otro; oír su voz, ya que el otro carecía de escritura. Eso es lo que el saber disciplinado, y sus importadores, no habían logrado hacer; el otro saber — saber del otro- resultaría, así, decisivo en la restauración del orden y del proyecto modernizador.

Digamos, por ahora, que la lectura (generalizada) de Sarmiento como un intelectual estrictamente importador del «capital simbólico» europeo no hace justicia a su complejidad, a sus contradicciones, sobre todo, en el Facundo ${ }^{9}$. La crítica sarmientina al saber europeo es marcada, aunque

'Esto ya lo había notado con lucidez Noé Jitrik, en Muerte y transfiguración de Facundo (Buenos Aires: Centro Editor de América Latina, 1968). Véase también su introducción al Facundo (Caracas: Biblioteca Ayacucho, 1973). 
a veces coexista con la ideología mimética más radical. Tampoco nos parece posible reducir esa distancia al desplazamiento que sufre el libro europeo en el trabajo de segunda mano que erige la cita. La distancia entre Sarmiento y su biblioteca no es solamente un punto ciego, una aporía en su discurso europeizante. Sarmiento es capaz de asumir esa distancia para legitimar un saber diferente, medio bárbaro, sugiere él mismo, pero acaso por eso mejor preparado para representar lo particular americano, es decir, la fragilidad de la «civilización» en un mundo dominado por la «barbarie».

En efecto, al menos el Facundo no explica el caos de la sociedad recién emancipada sólo como carencia del discurso europeo. En cambio, en el relato de la historia que elabora Sarmiento, los «bárbaros» 1legan al poder por el error de la «civilización», de la ciudad, que había pretendido importar los modelos europeos sin tomar en cuenta la realidad particular - la barbarie - del mundo donde esos discursos debían operar. El vacío entre el discurso importado y la particularidad que quedaba excluida por aquella representación es el núcleo generador de las contradicciones, del caos actual:

En la República Argentina se ven a un tiempo dos civilizaciones distintas en un mismo suelo: una nasciente, que sin conocimiento de lo que tiene sobre su cabeza está remedando los esfuerzos ingenuos y populares de la Edad Media; otra, que realiza los últimos resultados de la civilización europea. El siglo xIx y el siglo XII viven juntos: el uno adentro de las ciudades, el otro en la campaña (p. 105).

La antítesis, en la lógica binaria de este discurso, prolifera: pies/ cabeza, campo/ciudad, tradición/modernidad. Pero el lugar de la autoridad, al menos en ese fragmento fundamental, no está en ninguna de las dos partes. Si tuviéramos que espacializar esa autoridad habría que decir que el sujeto habla desde la ciudad de provincia, entre ambos mundos contrapuestos. Porque Sarmiento enfatiza la ignorancia del «saber» urbano (Buenos Aires) ante la realidad local, «bárbara». Insiste en que es por causa de esa ignorancia, por esa falta de representación entre los dos mundos, por lo que la «barbarie», excluida por la «cultura», invadía las ciudades, anulando el grado de modernidad que las mismas habían 10grado.

E1 Facundo representa la historia como un progreso, como una modernización interrumpida por la catástrofe del caudillismo, que desarticulaba el sentido, la unidad nacional. Constituye así un intento de controlar la contingencia, el accidente, lo irracional de la barbarie, para reorganizar la «homogeneidad» (y el estado) nacional. Pero el proyecto de orde- 
nar el caos no podía basarse estrictamente en la importación de modelos, en la cita del libro europeo. Para restaurar había que escuchar la voz del otro, la tradición que el proyecto modernizador, inicialmente mimético (bajo Rivadavia) había ignorado. Había que representar lo que el saber europeo (o sus importadores) desconocían.

Escribir, en Sarmiento, es ordenar, modernizar; pero a la vez es un ejercicio previo y sobredeterminante de esa virtual modernización: escribir es transcribir la palabra (oral) del otro, cuya exclusión del saber (escrito) había generado la discontinuidad y la contingencia del presente. Escribir era mediar entre la civilización y la barbarie. Porque la restauración de la ciudad, de la vida pública racionalizada, no sería posible sin la mutua representación de aquellos dos mundos cuya fricción había desencadenado el caos, la interrupción de la modernización. Había que «revelar las costumbres nacionales, sin lo cual es imposible comprender nuestros personajes políticos ni el carácter primordial y americano de la sangrienta lucha que despedaza a la República Argentina» (p. 107).

Para reordenar la vida pública (en la barbarie «no hay res publica» [p. 84]) había que incorporar — no alienar- al otro. Y el primer paso hacia esa incorporación era la representación de la barbarie. Había que oír los cuentos del otro, hasta entonces desconocidos por el «saber» letrado:

Los hechos están ahí consignados, clasificados, probados, documentados; fáltales, empero, el hilo que ha de ligarlos en un solo hecho, el soplo de vida $[\ldots]$. Fáltame para intentarlo interrogar el suelo $[\ldots]$; oír las revelaciones de los cómplices, las deposiciones de las víctimas, los recuerdos de los ancianos, las doloridas narraciones de las madres que ven con el corazón; fáltame escuchar el eco confuso del pueblo, que ha visto y no ha comprendido, que ha sido verdugo y víctima, testigo y actor; falta la madurez del hecho cumplido, y el paso de tna época a otra, el cambio de los destinos de la nación, para volver con fruto los ojos hacia atrás, haciendo de la historia ejemplo y no venganza (p. 64).

En Sarmiento operan dos modos contradictorios de representar el pasado. Opera, por un lado, la visión del mundo oral de la tradición como aquello que había que eliminar si se deseaba modernizar (o «civilizar»: expandir la ciudad). Y, por otro, la visión de esa voluntad de ruptura como generadora de nuevos conflictos y ansiedades ${ }^{10}$, sobre todo después

${ }^{10} \mathrm{La}$ ansiedad ante el cambio y la ruptura de lo tradicional encuentra un emblema notable en la actitud de Sarmiento cuando las hermanas arrancan el árbol, símbolo de la tradición, en Recuerdos de provincia: «La edad madura nos asocia a todos los objetos que nos rodean (...), un árbol que hemos visto nacer, crecer y llegar a la 
que la «tradición» responde violentamente. La contradicción entre ambas versiones del pasado nunca se resuelve completamente ${ }^{11}$. De ahí la ambiguiedad fundamental en la representación del bárbaro ${ }^{12}$. A pesar de esa ambiguiedad irreductible, nos parece que el Facundo, según vemos en el fragmento citado anteriormente, busca conciliar el proyecto modernizador con el pasado, busca «volver los ojos hacia atrás»; mirar hacia atrás (no sólo hacia el futuro, como en las teleologías iluministas), para oír la voz del pueblo (la madre) y así darle al discurso de este nuevo saber el «soplo de vida» que no había logrado incorporar el libro europeo (la clasificación, los datos, los documentos). Oír al otro, su voz confusa, para tejer la continuidad, el "paso de una época a otra», que faltaba en la catástrofe actual, en el presente de la escritura.

Oír, entonces, es la técnica de un ejercicio historiográfico. $\mathrm{Y}$ era la literatura, como señala L. Gossman con respecto a la historiografía romántica europea, un discurso ejemplar para ese proyecto historiográfico de escuchar la voz de la tradición ${ }^{13}$. Así postula Sarmiento el rol posible de la literatura en las nuevas naciones:

Si un destello de literatura nacional puede brillar momentáneamente en las nuevas sociedades americanas, es el que resultará de la descrip-

edad provecta, es un ser dotado de vida (...) que nos acusa de ingratos, y dejaría un remordimiento en la conciencia si lo hubiésemos sacrificado sin motivo legítimo» (p. 114). La escritura proyectaba arrancar el árbol, pero a la vez debía llenar el vacío que la modernización efectuaba.

${ }^{11}$ En cuanto a la ambiguiedad de Sarmiento ante el pasado, cfr. Tulio Halperín Donghi, «Prólogo» a D. F. Sarmiento, Campaña en el Ejército Grande aliado de Sud América (México: Fondo de Cultura Económica, 1958), particularmente pp. XIX y siguientes.

${ }_{12}$ En un trabajo sobre la representación del «otro» en la historiografía (y literatura) romántica europea, Lionel Gossman señala cómo la «barbarie», externa al discurso, es a la vez la condición de posibilidad de la escritura histórica. En cuanto a Sarmiento, resulta importante este comentario de Gossman: «In many respects the tension between veneration of the Other - that is to say, not just the primitive or alien, but the historical particular, the discontinuous act or event in its irreducible uniqueness and untranslatableness, the very energy of "life" which no concept can encompass - and eagerness to repeat it, translate it, represent it, and thus, in a sense, domesticate and appropriate it, can be seen as the very condition of the romantic historian's enterprise. For the persistence of at least a residual gap between "original" and translation, between "Reality" or the Other and our interpretation of it, is what both generates and sustains the historian's activity, rather as the condition of history itself (...)» («History as Decipherment: Romantic Historiography and the Discovery of the Other», en New Literary History, vol. 18 [1986-1987], p. 40).

${ }^{13}$ L. Gossman, op. cit. Véase también su «The Go-Between: Jules Michelet, 1798$1874 »$, en $M L N, 89$ (1974), pp. 503-541. 
ción de las grandiosas escenas naturales, y sobre todo de la lucha entre la civilización europea y la barbarie indígena, entre la inteligencia y la materia; lucha imponente en América, y que da lugar a escenas tan peculiares, tan características y tan fuera del círculo de ideas en que se ha educado el espíritu europeo, porque los resortes dramáticos se vuelven desconocidos fuera del país [...] (p. 89).

La literatura era el lugar adecuado para la mediación necesaria entre la civilización y la barbarie, la modernidad y la tradición, la escritura y la oralidad. De ahí que la falta de «disciplina» y «documentación» -ligada a la espontaneidad, a la cercanía de la vida que Sarmiento relaciona con la literatura - sea en realidad un dispositivo de otro tipo de autoridad intelectual, más capacitada para representar y resolver el desorden que el «sabio» de corte europeo.

Ahora bien: no deja de ser significativo que desde la época de su publicación se haya problematizado la función «literaria» del Facundo, para oponerla a la autoridad - y al imperativo- de un discurso «verdadero» o «histórico». En su lectura del libro, Valentín Alsina, por ejemplo, relaciona los «defectos» del Facundo con sus proliferantes deslices literarios:

Le diré que en su libro, que tantas y tan admirables cosas tiene, me parece entrever un defecto general -el de la exageración-: creo que tiene mucha poesía, si no en las ideas, al menos en los modos de locución. $U d$. no se propone escribir un romance, ni una epopeya, sino una verdadera historia social [...] (énfasis nuestro) ${ }^{14}$.

La escisión entre "poesía» (y ficción) y «verdadera historia social» es. históricamente muy significativa. La dicotomía revela, ya a mediados de siglo, cierta tendencia a la autonomización de las funciones discursivas. Asimismo, registra una notable jerarquización, en el interior de una economía utilitaria del sentido, en la cual la literatura figura como un modo devaluado de representación, subordinado a la autoridad política de las formas más «modernas» $\mathrm{y}$ «eficientes» de la «verdad».

La respuesta de Sarmiento a Alsina es sumamente ambigua. En todo caso, Sarmiento le asegura que no retocaría la obra, y asume el «defecto» de la «espontaneidad», de la «poesía», como un complemento de su escritura de la historia. Modo que, al no basarse sólo en la racionalidad europea -en la escritura de la ciudad-, podía llegar a escuchar la voz.

${ }^{14}$ Valentín Alsina, «Notas» (sobre el Facundo), apéndice a la edición de la Biblioteca Ayacucho (Caracas, 1973), p. 255. 
alienada del otro, para así incluirla en el orden de un (nuevo) discurso. La «informalidad», la «inmediatez», la «indisciplina» de1 Facundo eran entonces las condiciones de posibilidad del acercamiento a la tradición (oral) «bárbara» que había que incorporar, representándola.

Ahora, yo pregunto: ¿qué impresiones ha de dejar en el habitante de la República Argentina el simple acto de clavar los ojos en el horizonte, y ver..., no ver nada? Porque cuanto más hunde los ojos en aquel horizonte incierto, vaporoso, indefinido, más se aleja, más lo fascina, lo confunde y lo surme en la contemplación y la duda. ¿Dónde termina aquel mundo que quiere en vano penetrar? ¡No lo sabe! ¿Qué hay más allá de lo que ve? La soledad, el peligro, el salvaje, la muerte. He aquí ya la poesía (p. 92).

La amenaza, el peligro que confronta el sujeto (y el Estado nacional) se relaciona, en el Facundo, con la ausencia de límites y estructuras. En efecto, el desierto es, en buena medida, el «enigma» cuya solución la escritura explora. Pero ante ese vacio distintivo del paisaje americano, la mirada «civilizada» y el saber racionalizador necesariamente flaquean. La mirada - y la autoridad- de la «poesía» comienza donde termina el mundo representable por la disciplina. De ahí que la literatura sea, para Sarmiento, una exploración de la frontera, una reflexión sobre los límites y los «afueras» de la ley.

Por otro lado, no conviene reducir el modo de representación que tanto Alsina como Sarmiento relacionan con la «poesía» al lirismo, que, de modo esporádico, por cierto, a veces opera en las descripciones sarmientinas. En términos del saber del otro y de la representación de la barbarie son aún más importantes los relatos, las narraciones que proliferan a lo largo del Facundo. Nos referimos, por ejemplo, a la notable historia de Navarro (Segunda parte, capítulo VII), el hombre «civilizado» que, perseguido por Quiroga, huye a las tolderías indígenas y se convierte en «otro»; al relato de la juventud de Quiroga y su lucha con un tigre (animal «otro» por excelencia), o al asesinato de Quiroga por Santos Pérez en Barranca-Yaco.

Esos relatos, con bastante regularidad, exploran temáticamente la experiencia del límite, la ambigüedad de sujetos atrapados entre dos territorios de identidad: la civilización y la barbarie. Cuentan, frecuentemente, historias de barbarización, como el relato del estanciero de «raza europea pura» (p. 85) en San Luis, que había sido dominado por las «supersticiones groseras» nativas y por el «vicio» del juego, otro atributo clave de la barbarie. Más importante aún, esos relatos son, casi siempre, 
materiales que Sarmiento escucha. Son relatos de tradición oral ${ }^{15}$, palabras de «storyteller» y «cuentos de fogón» que Sarmiento escucha y colecciona.

De ahí que el Facundo sea un gran depósito de voces, relatos orales, anécdotas, cuentos de otros, que Sarmiento «transcribe» y acomoda en su representación de la barbarie. Como si esas palabras-otras indicaran la presencia, la representación del otro -el excluido y ahora poderosoen el orden del discurso, en la vida racionalizada de la ciudad. Como si, efectivamente, la mediación entre los dos mundos funcionara y la escritura (de la voz), en la misma superficie de su forma, en la incorporación de la palabra y del cuento oral, resolviera la contradicción que generaba el caos. ¿Se trata, entonces, de un espacio discursivo democrático, «dialógico», donde la voz tradicional coexiste con las autoridades modernas? ¿Conlleva la representación la presencia de la «voz»?

Tendríamos ahora que preguntarnos cómo se representa la voz del otro y qué transformaciones sufre la «fuente» popular al ser incorporada a la escritura. Habría que ver, en la superficie de la forma (incluso tipográfica), la distancia o cercanía entre la voz representada, a veces incluso citada, y el sujeto de la escritura. Porque la re-presentación, aun cuando busca contener al otro, al asumirlo como objeto del discurso, nunca es un hecho pasivo. Y esa puesta en forma de la voz en la escritura es ideológicamente fundamental en el Facundo.

Para Sarmiento, la barbarie no representa siempre un exterior absolutamente vacío de sentido. Sin duda, su visión de la barbarie está minada de contradicciones, pero hay varios fragmentos matrices del Facundo - los cuadros costumbristas, sobre todo- en los cuales se enfatiza el saber del gaucho y la cultura campesina. En efecto, saber y conocer son palabras clave en esos antológicos cuadros. El bárbaro tiene palabra, tiene valor en términos de la producción del sentido. El gaucho «rastreador» tiene su «ciencia casera y popular» (p. 96). El «gaucho malo» tiene

${ }^{15}$ Cfr. Walter Benjamin, «The Storyteller (Reflections on the works of Nikolai Leskov», en H. Arendt (ed.), Illuminations, trad. por H. Zohn (New York: Schocken Books, 1969), pp. 83-109. La hipótesis central de Benjamin es que el relato oral encarna un tipo de experiencia y de comunicación que deviene en crisis en la sociedad moderna. Para Benjamin, la narración, en tanto modo de saber tradicional, se opone a la información. El concepto de "saber narrativo», en J. F. Lyotard, también se opone a la «ciencia» y a los discursos del saber moderno. Cfr. The Postmodern Condition: A Report on Knowledge, trad. por G. Bennigton y B. Massumi (Minneapolis: University of Minnesota Press, 1979), particularmente pp. 18-23. De Lyotard, sobre el «saber narrativo", véase también La posmodernidad (explicada a los niños), traducida por E. Lynch (Barcelona: Editorial Gedisa, 1987), especialmente el capítulo «Misiva sobre la historia universal», pp. 35-47. 
su «ciencia del desierto» (p. 102). E1 «baqueano» «conoce la ciénagas» (p. 99), «sólo él sabe» (p. 100), y ese saber es indispensable para el ejército. Es el «cantor», sin embargo, quien maneja un saber tradicional superior, ligado a su poesía «original» $\mathrm{y}$ «primitiva»:

[E1 cantor] está haciendo candorosamente el mismo trabajo de crónica, costumbres, historia, biografía, que el bardo de la Edad Media, y sus versos [orales] serían recogidos más tarde como los documentos y datos en que habría de apoyarse el historiador futuro, si a su lado no estuviese otra sociedad culta [...] (p. 105).

No obstante, la poesía del cantor, si bien cercana al origen, es «pesada, monótona, irregular, cuando se abandona a la organización del momento» (pp. 106-7). Aunque el «historiador futuro» (el propio Sarmiento) debía oír la voz, para no alienarla, asimismo debía someterla a la forma superior del discurso regular, independiente de la inspiración del momento. En el Facundo, entre «escuchar el eco confuso del pueblo» (p. 64) y escribir, media el «transcriptor», que rara vez cita al otro; el transcriptor, cuyo lugar nunca es neutro en el espacio jerarquizado del discurso.

La unidad menor en la representación del «discurso» del otro es la incorporación, en la escritura, de la palabra campesina. Incluso en el caso de esas transcripciones menores, la palabra campesina aparece con marcas que enfatizan la distancia, su extrañeza. Al asumir la voz, Sarmiento usa la bastardilla sistemáticamente: "¡Dónde te mias-dir!'» (p. 98), «es un parejo pangaré» (p. 103) o «se provee de los vicios» (p. 102). Hay un notable recocijo en la enunciación, en la aprehensión de la palabra «extraña», de la que a la vez se distancia el sujeto. El énfasis desnaturaliza la voz, a la vez que registra su funcionamiento fuera del contexto habitual. Se trata de la traducción de la palabra tradicional para un destinatario que, aunque no sabe, debía conocer al otro. Se trata, nuevamente, de la importancia de la mediación entre los dos mundos en pugna. Pero la actividad del mediador - nunca transparente- de ningún modo proyecta la presencia de la palabra «extraña»; en cambio, indica su traslado y transformación: su puesta en orden.

En un nivel superior, la distancia entre los dos léxicos, uno "propio» (escrito) y otro "extraño» (oral), se comprueba entre dos saberes jerarquizados. El «saber» del otro es «irregular», «confuso»: estaba sujeto a la «organización del momento» - a la particularidad-, que le impedía convertirse en reflexión generalizadora. El sujeto en el Facundo asume el relato oral como fuente de la escritura, pero a la vez desplaza y subordina 
la particularidad de esas voces bajo un saber generalizador, del cual, precisamente, carecía el «bárbaro».

En efecto, Sarmiento explícitamente defiende la necesidad de oír la voz «confusa» del otro - en el lugar de la «poesía»— ante el requisito de verdad y de saber moderno, racionalizado, que le imponía su mundo. Sin embargo, también es cierto que la dicotomía utilitaria entre "romance» $\mathrm{y}$ «verdadera historia social» también tiende a regular y a jerarquizar la producción del sentido en el Facundo.

Aunque los relatos orales resultaban indispensables, en tanto «documentos» alternativos, a su vez esos relatos constituían un suplemento peligroso. Los relatos contaminaban el discurso de la verdad, desviándolo de la racionalidad y disciplina que requería aquella economía «moderna» del sentido. Y, sobre todo, esos relatos consignaban —en el espacio mismo de la escritura - resabios de un saber narrativo, es decir, restos de aquello mismo que la escritura racionalizadora pretendía dominar. De ahí que el proyecto sarmientino de construir un archivo (ordenador) de la tradición oral suponía, para la escritura, el riesgo de su propia barbarización. Por eso la irreprimible tendencia de Sarmiento a narrar - a contar cuentos de otros - le produce una notable ansiedad, que a veces lo lleva a considerar el Facundo como «un caos discordante» que había que ordenar y purificar antes de que allí saliera, en el futuro, «depurada de todo resabio, la historia de nuestra patria» (p. 62).

A su vez, ante esas tensiones sociales que sobredeterminan la misma composición del libro, la escritura intenta sistematizar su gesto ordenador. La escritura responde a la peligrosidad de la dispersión y del «resabio» oral demarcando los cuentos, comentándolos y subordinado la particularidad y ambigüedad del saber narrativo bajo la función generalizadora y universalizante de un discurso supuestamente «moderno».

En el capítulo «Infancia y juventud de Juan Facundo Quiroga» encontramos un ejemplo notable de cómo la anécdota, soporte del discurso, es subordinada a la generalización. El capítulo comienza con el relato de la lucha entre un tigre y el joven Quiroga, quien aparece citado: «'Entonces supe qué era tener miedo', decía el general don Juan Facundo Quiroga, contando a un grupo de oficiales este suceso.» Claro está, como ocurre siempre, la procedencia del relato no se indica hasta su conclusión, y el límite entre el lugar del «transcriptor» y la voz del otro es impreciso. Al terminar la anécdota, sin embargo, se enfatiza la distancia:

También a él le llamaron Tigre de los Llanos, y no le sentaba mal esta denominación, a fe. La frenología o la anatomía comparada han demostrado, en efecto, las relaciones que existen entre las formas exteriores y las disposiciones morales [...] (p. 138). 
El paso de la anécdota a la frenología y a la anatomía comparada, es decir, del discurso particularizado al «saber» abstracto y general, comprueba la distancia entre dos autoridades distintas, jerarquizadas. El desliz se evidencia nuevamente en los párrafos siguientes al relato del tigre, cuando Sarmiento lee el rostro de Quiroga, los detalles de su fisonomía, como matices de un paisaje selvático. En las «sombras espesas» del rostro, en el «bosque de pelo», en las «pobladas cejas» (p. 138), Sarmiento lee el paisaje de la barbarie. De lo particular al tableau vivant: el procedimiento es sistemático y atraviesa el mismo concepto de la biografía que opera en Sarmiento: lo individual, lo particular, significa sólo en función del cuadro general, que a su vez posibilita la interpretación de lo particular. La escritura continuamente busca generar modelos que le permiten interpretar toda particularidad, toda variedad, remitiéndola a la generalidad preestablecida. Por ejemplo, la heterogeneidad definitoria de la barbarie, a lo largo del Facundo, será siempre subordinada a los cuatro cuadros paradigmáticos que Sarmiento había establecido desde el principio. «Si el lector se acuerda de lo que he dicho del capataz de carretas, adivinará el carảcter, valor y fuerza del Boyero [...]» (p. 240). «Es un Tirteo que anima al soldado con canciones guerreras, el cantor de que hablé en la primera parte [...]» (p. 190). Y, sobre Facundo, «¿Dónde encontraréis en la República Argentina un tipo más acabado del ideal del gaucho malo?» (p. 216). Los ejemplos se multiplican, comprobando la voluntad de subordinar lo particular al modelo en los "cuadros vivos», que a la vez serán como soportes que controlan la tendencia a la dispersión de este discurso, donde proliferan las anécdotas y el «saber» particularizado de los relatos orales, cuentos de otros.

Entonces, el «cuadro vivo» es más que el sitio adecuado para oír la voz «confusa» e "irregular» del otro. El cuadro es efecto de una práctica ordenadora que responde, formalmente, al proyecto de someter la heterogeneidad de la barbarie al orden del discurso ${ }^{16}$. «La inteligencia vence a la materia, el arte al número» (p. 236). Esa es la función de los cuadros sobre el rastreador, el baqueano, el gaucho malo y el cantor: si bien comprueban cierta búsqueda del origen, la postura del sujeto que mira hacia atrás, su operación confirma la voluntad racionaliazdora que impulsa a esta escritura.

Había que representar al otro. Pero la «confusión», la «irregularidad»

${ }^{16}$ Sobre los «cuadros vivos» señala M. Foucault: "The first of the great operations of discipline is, therefore, the constitution of the tableaux vivants, which transform the confused, useless or dangerous multitudes into ordered multiplicities» (Discipline and Punish. The Birth of the Prison, trad. por Alan Sheridan [New York: Vintage Books Edition, 1979], p. 148). 
de la voz, era precisamente una fuerza que se resistía a la representación. Porque la barbarie es lo otro de la representación, es el exterior temido del discurso. Por eso no bastaba con «escuchar» los registros de aquella realidad dispersa y amorfa. Había que someterla, ejercer la violencia de la forma sobre la irregularidad de la voz. Representar al bárbaro, en Sarmiento, presupone el deseo de incluirlo para subordinarlo a la generalidad de la ley de la «civilización»; ley, asimismo, de un trabajo racionalizado y «productivo», sujeto a las necesidades del mercado emergente.

Es decir, el procedimiento formal de incluir la palabra hablada del otro, para subordinarla a una autoridad superior, configura un intento de resolución - a nivel de la disposición misma de la materia discursivade una contradicción sobre la cual el Facundo continuamente reflexiona: la falta de la ley en aquella sociedad basada en la irregularidad y arbitrariedad del caudillo:

La sociedad ha desaparecido completamente, queda sólo la familia feudal, aislada, reconcentrada; y no habiendo sociedad reunida, toda clase de gobierno se hace imposible; la municipalidad no existe, la policía no puede ejercerse y la justicia civil no tiene medios de alcance a los delincuentes [...] (pp. 82-83).

En efecto, la barbarie es el exterior de los espacios disciplinados de la ley. El caudillo, para imponer su poder sobre la ciudad, destruye «toda regularidad en la administración. El nombre de Facundo llenaba el vacío de las leyes; la libertad y el espíritu de la ciudad habían dejado de existir» (p. 273). El «bárbaro [viola] todas las formas recibidas, pactos, tratados, capitulaciones [...]» (p. 248). Dicho de otro modo, viola los lugares de la ley escrita:

Lo que 1a República Argentina necesita antes de todo, lo que Rosas no le dará jamás, porque ya no le es dado darle, es que la vida, la propiedad de los hombres, no esté pendiente de una palabra indiscretamente pronunciada [...] Apenas hay un pueblo en América que tenga menos fe que el argentino en un pacto escrito, en una Constitución (p. 355; énfasis nuestro).

El Facundo, al oír y someter la palabra pronunciada del otro, anticipa ese orden racionalizado, que, como han señalado Weber y Poulantzas ${ }^{17}$,

${ }^{17}$ Cfr. M. Weber, «The Nature of Modern Capitalism», en Capitalism, Bureaucracy and Religion, ed. y trad. de S. Andreski (London: George, Allen and Unwin, 1983), pp. 109-111, y N. Poulantzas, Estado, poder y socialismo, trad. por F. Claudin (México: Siglo XXI, 1979), particularmente pp. 59-108. 
reconoce en el dominio de la ley escrita una condición de posibilidad. En ese sentido, también el Facundo comprueba la «función estatal» de la literatura, que J. Ludmer ha explorado en la poesía gauchesca, género que continuamente reflexiona y polemiza sobre la autoridad de la ley escrita:

El género tiene, en una de sus zonas, la función de reformular las relaciones jurídicas, de unificar jurídica y políticamente la nación: esa función estatal la cumple la literatura argentina desde la Independencia hasta la constitución definitiva del Estado en 1880; al género gauchesco le cabe sobre todo la integración de las masas rurales. La autonomía de la literatura (su separación de la esfera política y estatal) es, pues, un efecto del establecimiento de lo político y del Estado como esferas separadas ${ }^{18}$.

Más allá de la Argentina, la hipótesis sobre la «función estatal» de la «literatura» nos parece fundamental para explicar los lugares tan híbridos de la escritura latinoamericana anterior al 80. Había, como decía Sarmiento, que ilustrar el Estado: «la inteligencia, el talento y el saber serán llamados de nuevo a dirigir los destinos públicos» (p. 353). Y aunque en la Argentina, dominada por la «barbarie», los letrados que se «habían preparado para la vida pública se encontraban sin foro, sin prensa, sin tribuna, sin esa vida pública» (p. 332), en otros países eran precisamente los letrados los que ya administraban, como señala Bello, el proceso de "[quitarle] a la costumbre la fuerza de la ley» ${ }^{19}$. Porque, añade Bello, «muchos de los pueblos modernos más civilizados han sentido la necesidad de codificar sus leyes», $y$ «se hace necesario refundir esta masa confusa de elementos diversos, incoherentes y contradictorios, dándoles consistencia y armonía y poniéndolos en relación con las formas vivientes del orden social».

Lo significativo, en Sarmiento, es que esa función racionalizadora de la escritura no es simplemente comprobable en términos temáticos, sino en la propia disposición de la palabra del otro, de la tradición, del saber particular, bajo la autoridad generalizadora que modela a la ley. Por eso decíamos que escribir, en Sarmiento, es modernizar. No se trata de una metáfora, de una analogía entre el campo del discurso y un orden social «reflejado»: ese orden social —la vida pública racionalizada— sólo asu-

18 Josefina Ludmer, «Quién educa», en Filología, año XX, 2, nota 5.

19 A. Bello, «Exposición de motivos» (1855), en Código Civil de la República de Chile, en Obras completas, tomo XII (Caracas, 1954), p. 4. 
me espesor en la escritura. Si en el momento en que se escribe el Facundo la modernización había sido interrumpida, si la vida pública era una carencia, y reinaba el caos, la escritura, en su operación generalizadora y homogeneizadora, era un modelo fundamental del proyecto racionalizador, así como registraba, en la misma heterogeneidad de su forma, las aporías que confrontó esa racionalización en América Latina. 
